\title{
Predictors and Outcomes of Invasive Mechanical Ventilation in Opioid Overdose Hospitalization in the United States
}

\author{
Adeolu O. Oladunjoye ${ }^{1,2}$, Olubunmi O. Oladunjoye ${ }^{3}$, Oluwatoyin Olubiyi ${ }^{4}$, Maria Ruiza Yee ${ }^{5,6,7}$, \\ Eduardo D. Espiridion 7, 8, 9, 10, 6 \\ 1. Medical Critical Care, Boston Children's Hospital, Harvard Medical School, Boston, USA 2. Psychiatry, Reading \\ Health Tower Health, West Reading, USA 3. Internal Medicine, Reading Hospital Tower Health, West Reading, USA 4. \\ Public Health, Philadelphia Department of Health, Philadelphia, USA 5. Psychiatry, Philadelphia Collge of Osteopathic \\ Medicine, Philadelphia, USA 6. Psychiatry, Reading Hospital Tower Health, West Reading, USA 7. Psychiatry, Drexel \\ University College of Medicine, Philadelphia, USA 8. Psychiatry, West Virginia School of Osteopathic Medicine, \\ Lewisburg, USA 9. Psychiatry, West Virginia University School of Medicine, Martinsburg, USA 10. Psychiatry, \\ Philadelphia College of Osteopathic Medicine, Philadelphia, USA
}

Corresponding author: Eduardo D. Espiridion, edjen19meg@gmail.com

\section{Abstract}

\section{Introduction}

Opioid overdose is increasingly becoming common and so is the need for invasive mechanical ventilation (IMV) for opioid overdose admissions in hospitalized patients. Respiratory failure requiring invasive mechanical ventilation is the most common reason for the admission of opioid-associated overdose patients. The aim of our study was to assess the demographic and clinical characteristics associated with the increased need for IMV in hospitalized opioid overdose patients.

\section{Methods}

We analyzed all adult admissions (18 years and above) using the National Inpatient Sample (NIS) database for five years from January 1, 2010-December 31, 2014 to identify opioid overdose patients requiring invasive mechanical ventilation. We compared the demographic and clinical characteristics of opioid overdose patients requiring and not requiring mechanical ventilator support and performed univariate and multivariate analyses to determine the odds ratio (OR) of association.

\section{Results}

A total of 2,528,751 opioid overdose patients were identified among which $6.4 \%$ required IMV during hospitalization. The prevalence of opioid overdose and the need for IMV increased by $31 \%$ and $38 \%$, respectively, over the study period. Multivariate logistic regression (OR (95\% CI), $p<0.001$ ) determined the following to be associated with increased odds of mechanical ventilator use: (OR 1.12 (1.06-1.19)) among

Received 07/30/2020

Review began 08/03/2020 Review ended 08/04/2020 Published 08/16/2020

\section{๑) Copyright 2020}

Oladunjoye et al. This is an open access article distributed under the terms of the Creative Commons Attribution License CC-BY 4.0., which permits unrestricted use, distribution, and reproduction in any medium, provided the original author and source are credited. patients aged 25-39 years vs (1.36 (1.28-1.44)) for the age group 40-64 years when compared to 18-24 years; hospital locations in the south US region (OR 1.62 (1.49-1.75)) when compared to the northeast US region; the presence of aspiration pneumonia (OR 14.30 (13.63-15.0)), rhabdomyolysis (3.22 (3.04-3.42)), septic shock (9.15 (8.41-9.97)), and anoxic brain injury (15.5 (13.70-17.50)). Other factors associated with decreased odds of IMV include hepatitis C virus infection (OR 0.75 (0.72-0.79)) and black race (OR 0.68 (0.63-0.74)]. Opioid overdose patients requiring IMV had a higher length of stay by $8.9 \pm 0.1$ days, higher hospitalization cost by US $\$ 28,117.81 \pm 373.53$, and higher in-hospital mortality rate $(13.4 \%$ vs $0.3 \%)$.

\section{Conclusion}

The prevalence of opioid overdose and the need for IMV increased over the five-year study period, reflecting an increase in the relatively high in-hospital mortality of opioid overdose patients on IMV. Patient's age, geographic location, race, and several comorbidities affect the need for invasive mechanical ventilation in hospitalized opioid overdose patients. These findings emphasize the need for a better understanding of these risk factors in creating a strategic approach for hospital care of opioid overdose patients.

Categories: Psychiatry

Keywords: hospitalization, opioid, opioid overdose, invasive mechanical ventilation

\section{Introduction}

Drug overdose is the leading cause of injury-related fatality in the United States (US) after a motor vehicle accident [1]. In 2018, 70\% of US drug overdose deaths involved opioid use [2]. Opioid overdose has been on the rise since the 1990s, leading to different waves of opioid-associated overdose deaths. Over a decade since the 2000s, the number of deaths has quadrupled [3]. The US health system has taken a hit with more than 9 
Billion dollars spent as of 2005 on the epidemic [3]. The second wave of the epidemic experienced a rapid rise in opioid overdose deaths, starting in 2010 with the increased use of heroin [4]. Unfortunately, the southwestern United States and Appalachia saw the largest per capita increase in the death rate due to drug overdose [5]. This second wave continued to rise and then the third wave took over in 2013 due to prescription or illicitly manufactured synthetic opioids, tramadol, and fentanyl made available to people presenting with pain in the healthcare facility [6].

While national attention is focused on the treatment given by first responders, not enough national attention is given to those who might need hospitalization to treat complications from an opioid overdose. The need for invasive mechanical ventilation (IMV) for opioid overdose admissions is increasing, as the opioid cases on hospitalization also increase. This has driven the overall cost of caring for these patients who need critical intensive care from about an average of $\$ 58,000$ in 2009 to $\$ 92,400$ in 2015 [7]. Respiratory failure requiring invasive mechanical ventilation is the most common reason for admissions of opioidassociated overdose [3]. This requirement has led to major causes of morbidity and mortality in hospitalized patients presenting with opioid overdose [1].

However, little is known about the predictors and outcomes of hospitalized patients who need mechanical ventilation during opioid overdose hospitalization. Therefore, we sought to assess the predictors and outcomes associated with the use of invasive mechanical ventilation in opioid overdose patients hospitalized in the United States.

\section{Materials And Methods Study design and data sources}

We analyzed all adult admissions (18 years and above) using the Healthcare Cost and Utilization Project National Inpatient Sample (HCUP-NIS) database from January 1, 2010, to December 31, 2014. This database is sponsored by the Agency for Healthcare Research and Quality (AHRQ). It is the largest all-payer publicly available inpatient care database made up of a $20 \%$ sample of US hospitalizations, from more than 40 (of the 50) states in the US providing a weighted estimate representing $>95 \%$ of the hospitalized population.

The International Classification of Diseases Ninth Revision Clinical Modification (ICD-9-CM) was derived from 15 procedure columns and 25-30 diagnoses columns, which were used to identify the study population. Since the database is de-identified and publicly available, ethical clearance or Institutional Review Board approval was not necessary.

\section{Study population and characterization of variables}

The following International Classification of Diseases Ninth Revision Clinical Modification (ICD-9CM) diagnosis codes were used to identify the diagnosis for opioid overdose patients: presence on admission of prescription overdose (ICD-9 965.00, 965.09, or E code E 850.0, E 850.1, and E850.2); heroin overdose (ICD-9 965.01, E 850.0, and E 935.0); methadone overdose (965.02); non-dependent opioid abuse (ICD-9 305.50,305.51, 305.52, and 305.53); and opioid type dependence (ICD-9 304.00, 304.01, 304.00, 304.01, 304.02, and 304.03) as used in previous literatures (Figure 1) [7-8]. We also identified procedure codes that enabled us to derive those who used invasive mechanical ventilation. These include 96.70, 96.71, 96.72, 31.1 and 31.29 . 
NIS database All records from year 2010-2014

Sample $n=37,312,324$ (weighted estimate, $N=181,755,884$ )

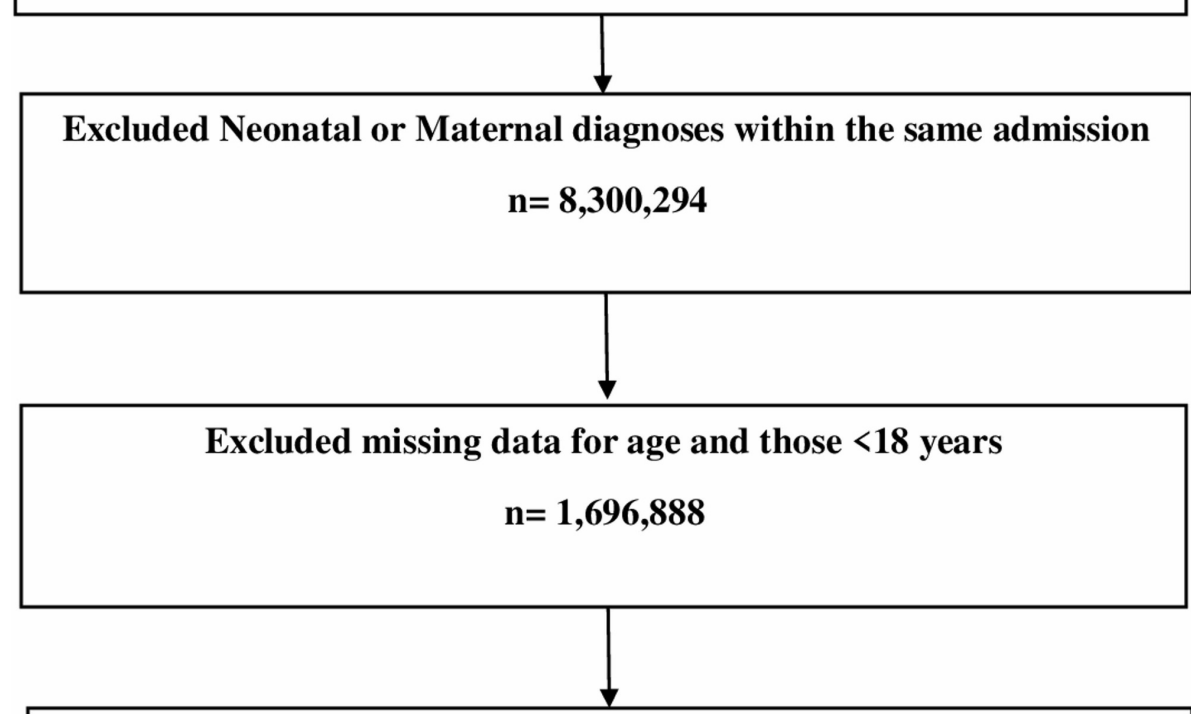

Identified hospital discharges with Opioid overdose using ICD-9-CM diagnosis codes: $965.00,965.01,965.02,965.09,305.50,305.51,305.52$, 305.53, 304.00, 304.01, 304.00, 304.01, 304.02, 304.03, E 850.0, E 850.1, E850.2, E935.0

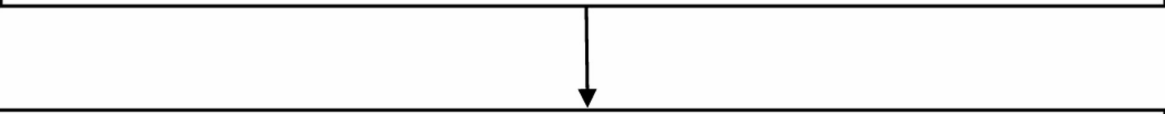

Identified patients requiring invasive mechanical ventilation using the ICD-9-CM procedure codes: 96.70, 96.71, 96.72, 31.1, 31.29

FIGURE 1: Flowchart for invasive mechanical ventilation in opioid overdose hospitalizations in the United States

Our primary outcomes of interest were assessing the demographic and clinical characteristics associated with the increased need for IMV in hospitalized opioid overdose patients. Our secondary outcomes of interest were the incidence of in-hospital mortality and the discharge disposition of hospitalized opioid overdose patients who needed IMV. We had two groups for comparison among the opioid overdose patients based on whether they used IMV or not during their hospitalization. Demographic and clinical characteristics were then compared to assess the difference between these two groups, with univariate and multivariate analyses reported to show their differences and associated statistical significance (OR 95\%CI; P $=0.005$ ).

We also sort to report the prevalence and hospitalization trends among opioid overdose patients and show trends for those who had IMV during their hospitalization. Tables and figures were generated to show our 


\section{Cureus}

results.

\section{Patient demographics and comorbidities}

Patients demographics include age (divided into 18-24, 25-39, 40-64 and 65+ years), race (white, black, and others), insurance provider (divided into government, private, self-pay, and others), income (divided into four quartiles), regions of the US (northeast, south, midwest/north-central, and west). Clinical characteristics were derived from the database for patients who had hepatitis C virus infection (HCV) (ICD-9 070.41, 070.44, 070.51, 070.54, 070.70, and 070.71) and complications of opioid overdose including aspiration pneumonia (ICD-9 507.0), septic shock (ICD-9 785.52), rhabdomyolysis (ICD-9 728.88), and anoxic brain injury (ICD-9 348.1 and 437.9).

\section{Statistical analysis}

All statistical analyses were performed using Stata version 15.0 (StataCorp, College Station, TX). We reported the mean and standard deviation for continuous variables. We used a P-value of $<0.05$ and a $95 \%$ confidence interval (CI). Statistical tests, such as the chi-square test and percentages, were used to report categorical variables. The student's t-test was used for numeric variables. Linear models were used to derive trend analysis using the Joinpoint regression analysis statistical software (Belleair Beach, Florida) to derive the annual percentage change (APC). The APC considers constant changes that occur over a specified period in which the rate of disease change is seen in relation to the years assessed in percentages. Joinpoint software takes trend data and, based on the maximum number of joinpoints supplied by the user, fits the data into segments, enabling the users to assess if the apparent change in trend is statistically significant [9]. All analyses were performed with strata and weight to account for the complex clustered sampling methodology.

\section{Results}

We studied a total of 2,528,751 opioid overdose patients identified for the five-year study period from January 1, 2010, to December 31, 2014, among which 162,345 (6.4\%) required IMV during hospitalization. There were $54.7 \%$ male, $69.6 \%$ white, and $52.5 \%$ of the total population aged $40-64$ years in these hospitalized patients. The mean age of overall patients is $44.6 \pm 0.1$ years. The demographic and clinical characteristics were compared between those who were and were not on IMV during their hospitalization for opioid overdose (Table 1).

\begin{tabular}{|c|c|c|c|c|}
\hline Name & $\begin{array}{l}\text { Overall }(n=516,268)(\mathrm{N}=2 \text {, } \\
528,751)\end{array}$ & $\begin{array}{l}\text { IMV }(n=33,061)(N= \\
162,345)\end{array}$ & $\begin{array}{l}\text { No IMV }(n=483,207) \\
(N=2,366,406)\end{array}$ & $\begin{array}{l}\text { P- } \\
\text { Value }\end{array}$ \\
\hline Mean Age ( $\pm S E), y$ & $44.6 \pm 0.1$ & $46.3 \pm 0.1$ & $44.4 \pm 0.1$ & $<0.0001$ \\
\hline Age, y & & & & $<0.0001$ \\
\hline $18-24$ & 9.2 & 7.6 & 9.3 & \\
\hline $25-39$ & 29.7 & 26.0 & 30.0 & \\
\hline $40-64$ & 52.5 & 56.9 & 52.3 & \\
\hline$\geq 65$ & 8.5 & 9.4 & 8.5 & $<0.0001$ \\
\hline \multicolumn{5}{|l|}{ Sex, \% } \\
\hline Male & 54.7 & 55.3 & 54.7 & \\
\hline Female & 45.3 & 44.7 & 45.3 & 0.1499 \\
\hline \multicolumn{5}{|l|}{ Race, \% } \\
\hline White & 69.6 & 75.5 & 69.2 & \\
\hline Black & 17.1 & 11.7 & 17.4 & \\
\hline Other & 13.3 & 12.8 & 13.4 & $<0.0001$ \\
\hline \multicolumn{5}{|l|}{ Comorbidities, \% } \\
\hline HCV & 16.7 & 15.1 & 16.9 & $<0.0001$ \\
\hline \multicolumn{5}{|l|}{ Complication } \\
\hline Aspiration Pneumonia & 3.7 & 28.9 & 1.9 & $<0.0001$ \\
\hline Septic Shock & 1.2 & 11.1 & 0.5 & $<0.0001$ \\
\hline
\end{tabular}




\section{Cureus}

\begin{tabular}{|c|c|c|c|c|}
\hline Rhabdomyolysis & 2.9 & 13.9 & 2.2 & $<0.0001$ \\
\hline Anoxic Brain Injury & 0.8 & 9.8 & 0.2 & $<0.0001$ \\
\hline \multicolumn{5}{|l|}{ Income, \% } \\
\hline First quartile & 35.0 & 35.3 & 35.0 & \\
\hline Second Quartile & 24.9 & 26.1 & 24.8 & \\
\hline Third Quartile & 23.4 & 22.6 & 22.3 & \\
\hline Fourth Quartile & 17.8 & 16.0 & 17.9 & $<0.0001$ \\
\hline \multicolumn{5}{|l|}{ Insurance, \% } \\
\hline Government & 60.7 & 60.0 & 60.7 & \\
\hline Private & 19.4 & 18.8 & 19.5 & \\
\hline Self-Pay & 13.6 & 15.4 & 13.5 & \\
\hline Others & 6.3 & 5.8 & 6.3 & $<0.0001$ \\
\hline \multicolumn{5}{|l|}{ Region, \% } \\
\hline North East & 27.2 & 19.2 & 27.7 & \\
\hline Mid-West/North Central & 21.2 & 21.0 & 21.2 & \\
\hline South & 31.2 & 36.4 & 30.9 & \\
\hline West & 20.4 & 23.4 & 20.2 & $<0.0001$ \\
\hline \multicolumn{5}{|l|}{$\begin{array}{l}\text { Hospital Teaching Status, } \\
\%\end{array}$} \\
\hline Rural & 7.9 & 8.1 & 7.9 & \\
\hline Urban Non-Teaching & 36.4 & 35.7 & 36.5 & \\
\hline Urban Teaching & 55.7 & 56.2 & 55.6 & 0.5961 \\
\hline \multicolumn{5}{|l|}{ Discharge Disposition, \% } \\
\hline Home/Home Health & 83.6 & 62.3 & 84.9 & \\
\hline Others & 16.4 & 37.7 & 15.1 & $<0.0001$ \\
\hline Length of Stay, Days & $5.3 \pm 0.1$ & $8.9 \pm 0.1$ & $5.1 \pm 0.0$ & $<0.0001$ \\
\hline Cost ( \pm SE) & $9673.67 \pm 138.70$ & $28117.81 \pm 373.53$ & $8412.97 \pm 122.32$ & $<0.0001$ \\
\hline Mortality, \% & 1.2 & 13.4 & 0.3 & $<0.0001$ \\
\hline
\end{tabular}

TABLE 1: Baseline characteristics of hospitalized opioid-associated overdose patients stratified by use of invasive mechanical ventilation (IMV)

n, sample number; N, weighted average; HCV, hepatitis $\mathrm{C}$ virus

\section{Patients with opioid overdose on IMV during hospitalization}

The prevalence of IMV use in opioid overdose increased year after year. It increased by $38 \%$ and the prevalence of opioid overdose increased by 31\% over the five-year study period. (Figures 2-3) 


\section{Cureus}

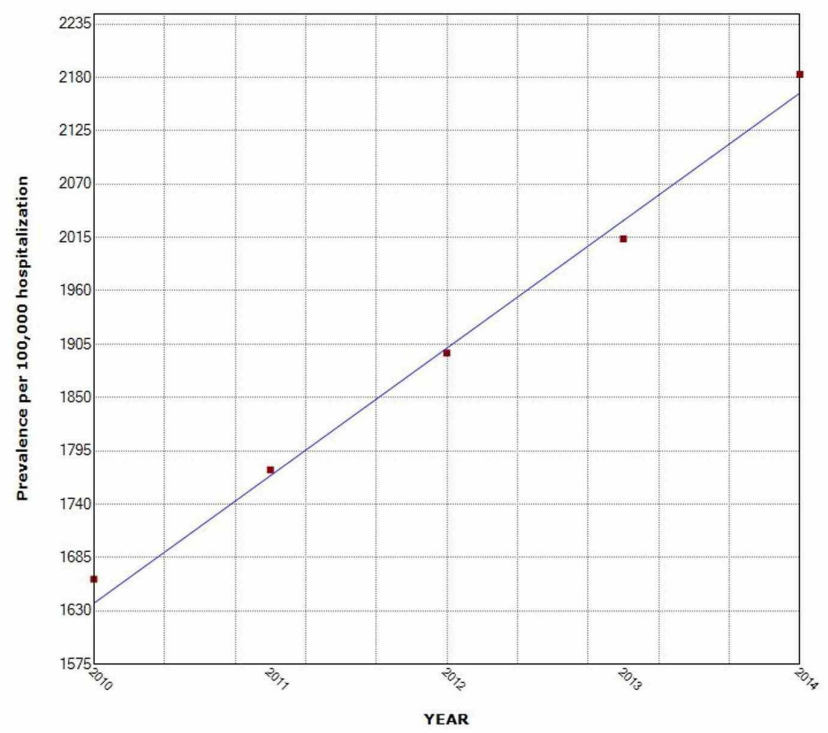

FIGURE 2: Increasing trend of opioid overdose hospitalization over the five-year study period

* indicates that the slope is significantly different from zero at the alpha $=0.05$ level. Final selected model: 0 Joinpoints

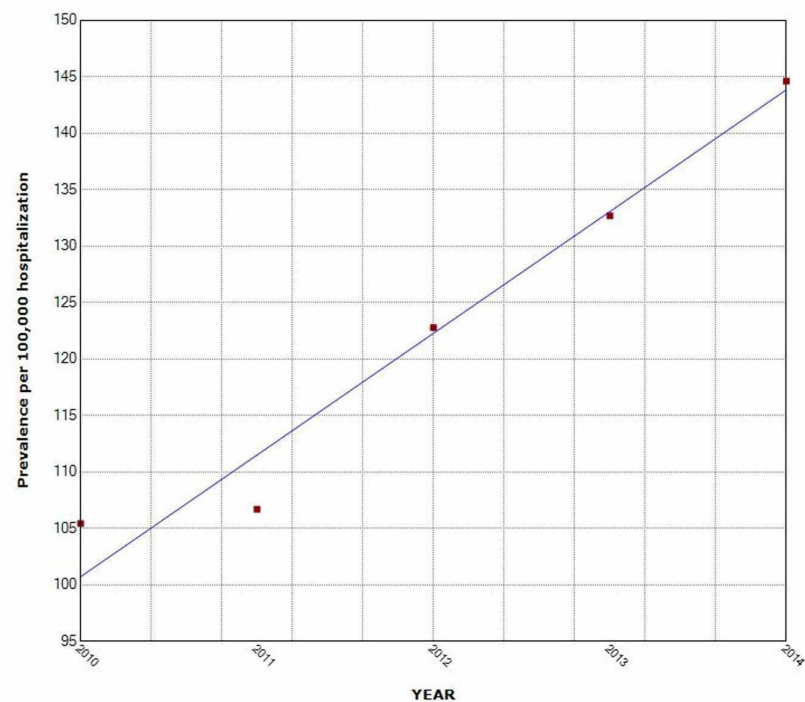

FIGURE 3: Increasing trend of opioid overdose hospitalization in those on IMV use over the five-year study period

* indicates that the slope is significantly different from zero at the alpha $=0.05$ level. Final selected model: 0 Joinpoints

IMV: invasive mechanical ventilation

After adjusting for other variables, multivariate logistic regression (OR $(95 \% \mathrm{CI}), \mathrm{p}<0.001)$ determined the following to be associated with increased odds of mechanical ventilator use: age group 25-39 years (OR 1.12 (1.06-1.19)) and 40-64 years (OR 1.36 (1.28-1.44)) as compared to 18-24 years; hospitals in the US south region (OR 1.62 (1.49-1.75)), US mid-west/north-central region (OR 1.57 (1.42-1.74)), and US west region (OR 1.38 (1.27-1.50)) as compared to the northeast region. However, there was no statistically significant difference in income, insurance, or hospital teaching status. 


\section{Cureus}

$2.9 \%$ had rhabdomyolysis, $1.2 \%$ had septic shock, and $0.8 \%$ had an anoxic brain injury. Also after adjusting for other variables, these comorbidities were associated with increased odds of mechanical ventilator use: aspiration pneumonia (OR 14.30 (13.63-15.0)), rhabdomyolysis (OR 3.22 (3.04-3.42)), septic shock (OR 9.15 (8.41-9.97)), anoxic brain injury (OR 15.5 (13.70-17.50)). However, on the other hand, those who had hepatitis $\mathrm{C}$ virus infection (OR 0.75 (0.72-0.79)) and black patients (OR 0.68 (0.63-0.74), had reduced odds of invasive ventilation $(\mathrm{p}<0.001)$ (Table 2$)$.

\begin{tabular}{|c|c|c|c|c|}
\hline Name & Univariate analysis (Crude OR) & P-Value & Multivariate analysis (Adjusted OR) & P-Value \\
\hline Mean Age ( \pm SE), y & $1.01(1.01-1.01)$ & $<0.0001$ & & \\
\hline \multicolumn{5}{|l|}{ Age, y } \\
\hline $18-24$ & Ref & & & \\
\hline $25-39$ & $1.08(1.01-1.13)$ & 0.018 & $1.12(1.06-1.19)$ & $<0.0001$ \\
\hline $40-64$ & $1.34(1.26-1.42)$ & $<0.0001$ & $1.36(1.28-1.44)$ & $<0.0001$ \\
\hline$\geq 65$ & $1.37(1.28-1.47)$ & $<0.0001$ & $1.01(0.93-1.09)$ & 0.7930 \\
\hline \multicolumn{5}{|l|}{ Sex, \% } \\
\hline Male & Ref & & & \\
\hline Female & $0.98(0.95-1.01)$ & 0.1510 & & \\
\hline \multicolumn{5}{|l|}{ Race, \% } \\
\hline White & Ref & & & \\
\hline Black & $0.61(0.56-0.67)$ & $<0.0001$ & $0.68(0.63-0.74)$ & $<0.0001$ \\
\hline Other & $0.88(0.83-0.93)$ & $<0.0001$ & $0.94(0.89-1.00)$ & 0.0410 \\
\hline \multicolumn{5}{|l|}{ Comorbidities, \% } \\
\hline HCV & $0.88(0.84-0.91)$ & $<0.0001$ & $0.81(0.77-0.85)$ & $<0.0001$ \\
\hline HBV & $0.99(0.89-1.11)$ & 0.8900 & & \\
\hline \multicolumn{5}{|l|}{ Complication } \\
\hline Aspiration Pneumonia & $20.6(19.7-21.6)$ & $<0.0001$ & 14.30 (13.63-15.01) & $<0.0001$ \\
\hline Septic Shock & $24.7(23.1-26.5)$ & $<0.0001$ & $9.15(8.41-9.97)$ & $<0.0001$ \\
\hline Rhabdomyolysis & $6.7(6.4-7.1)$ & $<0.0001$ & $3.22(3.04-3.42)$ & $<0.0001$ \\
\hline Anoxic Brain Injury & $69.1(63.1-75.7)$ & $<0.0001$ & 15.5 (13.70-17.50) & $<0.0001$ \\
\hline \multicolumn{5}{|l|}{ Income, \% } \\
\hline First quartile & Ref & & & \\
\hline Second quartile & $1.04(1.00-1.09)$ & 0.0710 & & \\
\hline Third quartile & $1.00(0.95-1.06)$ & 0.9170 & & \\
\hline Fourth quartile & $0.89(0.83-0.95)$ & $<0.0001$ & & \\
\hline \multicolumn{5}{|l|}{ Insurance, \% } \\
\hline Government & Ref & & & \\
\hline Private & $0.97(0.93-1.02)$ & 0.2940 & & \\
\hline Self- Pay & $1.15(1.06-1.25)$ & 0.0010 & & \\
\hline Others & $0.93(0.86-1.02)$ & 0.1220 & & \\
\hline \multicolumn{5}{|l|}{ Region, \% } \\
\hline North East & Ref & & & \\
\hline Mid-West/North Central & $1.43(1.28-1.60)$ & $<0.0001$ & 1.57 (1.42-1.74) & $<0.0001$ \\
\hline
\end{tabular}




\section{Cureus}

\begin{tabular}{|c|c|c|c|c|}
\hline South & $1.70(1.55-1.86)$ & $<0.0001$ & $1.62(1.49-1.75)$ & $<0.0001$ \\
\hline West & $1.67(1.53-1.82)$ & $<0.0001$ & $1.38(1.27-1.50)$ & $<0.0001$ \\
\hline \multicolumn{5}{|c|}{ Hospital Teaching Status, \% } \\
\hline Rural & Ref & & & \\
\hline Urban Non-Teaching & $0.96(0.87-1.05)$ & 0.3910 & & \\
\hline Urban Teaching & $0.99(0.90-1.09)$ & 0.8450 & & \\
\hline Length of Stay, Days & $1.03(1.04-1.05)$ & & $1.04(1.03-1.04)$ & $<0.0001$ \\
\hline$\geq$ Mortality, \% & $44.80(41.78-48.06)$ & & $20.17(18.34-22.18)$ & $<0.0001$ \\
\hline
\end{tabular}

\section{TABLE 2: Factors associated with invasive mechanical ventilators in hospitalized opioid- associated overdose patients}

HCV, hepatitis C virus; HBV, hepatitis B virus

\section{Cost and mortality of opioid overdose on IMV during hospitalization}

The hospitalization costs associated with IMV use were significantly higher than those without IMV $(28,117.81 \pm 373.53$ vs $8412.97 \pm 122.32)(p<0.001)$. Opioid overdose patients requiring IMV also had a higher length of stay by $8.9 \pm 0.1$ days as compared to those who were not on IMV $5.1 \pm 0.0$ days even after adjusting for other variables $(\mathrm{p}<0.001)$ (Table 2$)$. Also, a higher in-hospital mortality rate $(13.4 \%$ vs $0.3 \%)$ can be seen in those on IMV ( $\mathrm{p}<0.001)$ and it remained so after adjusting for other factors (OR 20.17 (18.34-22.18) $(\mathrm{p}<0.001)$ (Table 2).

\section{Discussion}

The increase in the prevalence of opioid overdose patients by $31 \%$ and in those on IMV by $38 \%$ during the study period, 2010-2015, is astronomically high. This also applies to the mortality rate, which is also on the increase. The number of opioid overdose deaths in 2018 is reported to be about six times the rate in 1999 [10]. Even though there was a slight decrease in death by $2 \%$ from $2017-2018$, this trend has continued to rise year after year.

Beginning with the baseline demographics, this study reports that white males and ages 40-64 years were the most hospitalized patients, and this is consistent with other similar studies where they have been predominantly white, male, older age groups admitted for opioid overdose [11-13]. However, an ICU study reported having more white females in their fifth decade [3]. Apart from age and gender, other risk factors have been identified as independent risk factors to consider. A study conducted among New York hospitals reported that white race and low level of poverty contributed to adverse fatal opioid overdose [14]. Our study also supports these findings where opioid overdose patients were more among those in the lowest quartile of income ( $\mathrm{p}<0.0001)$. Although after adjusting for other factors, this statistical significance was lost.

Much of the emphasis on the prevention of opioid overdose has been on the need to equip bystanders and emergency workers, such as emergency medical technician staff and the police, on the need to give naloxone on the field when a person is suspected to have overdosed [15-16]. However, the critical care needs of hospitalized patients with opioid overdose is beginning to gain more traction especially in areas where the cases of overdose victims are still very high [7]. This study clearly addresses the need to provide interventions that support more critical care resources and the expansion of primary prevention measures. The use of mechanical ventilation is said to be higher among opioid overdose patients as compared to other forms of drug overdose [17]. Two smaller sample size ICU studies with 178 and 42 opioid overdose patients reported that $85 \%$ and $88 \%$ of admissions in the ICU required IMV, respectively $[3,18]$. On the other hand, our large study reported that 162,345 out of about 2,528,751 opioid overdose patients on hospitalization required IMV intervention. The disparity in numbers might be because our study compared rates with all hospitalized patients with opioid overdose rather than just those in the ICU.

Another thing to consider, especially when IMV is needed in hospitalized patients, is the cost of hospital care. As was earlier stated, the overall cost of caring for opioid overdose patients in the ICU increased from an average of $\$ 58,000$ in 2009 to $\$ 92,400$ in 2015 , which is about $58 \%$ more in spending per patient [7]. A study that was the first to be done in New York City to describe ICU resource utilization in patients with acute drug overdose averaged the cost of care for patients with acute drug intoxication to be about $\$ 16,080$ per patient higher than many other studies compared [17]. This differs, however, from the average cost of our hospitalized patient, which is about $\$ 9,674$, and similar to other studies [3,17]. However, in our patients who had IMV, the cost of hospital care was much higher $(\$ 28,117 v \$ 8,413)(p<0.0001)$. This further 
emphasizes the need for better strategies to limit spending and hospital costs, especially in potential IMV users. Examples of such measures will include the screening of high-risk comorbidities and the screening of those with baseline demographic predictors early during hospitalization. This will ensure that clinicians provide early airway management and keep a close watch on such patients to prevent complications during hospital care of opioid overdose patients.

The most seen complications among hospitalized patients were assessed in our study. Our findings were stunning. Even after adjusting for other predictors, these complications were associated with increased odds of IMV use. In our study, the most common complication was aspiration pneumonia (3.7\%) followed by rhabdomyolysis (2.9\%) and then septic shock and anoxic brain injury (1.2\% and $0.8 \%$ respectively). A study similarly found these complications among opioid overdose patients admitted in the ICU. About a quarter experienced aspiration pneumonia while $15 \%$ had rhabdomyolysis, $8 \%$ had an anoxic brain injury and $6 \%$ had septic shock [7]. If these complications are not taken care of early, they may lead to an increase in the mortality rate.

The causes of death in an ICU study by Pfister showed that brain injury accounted for more than half of mortality cases, acute respiratory failure was responsible for about a quarter, and the other causes of death were myocardial infarction and sepsis [3]. The mortality rate of those who were on IMV (13.4\%) compares relatively to those in a related ICU study put at $10.1 \%$ [3]. However, the overall mortality rates in our study and in the no IMV group were relatively low (1.2\% and $0.3 \%$, respectively) as compared to those who were on IMV (13.4\%). Another factor that was considered during analysis was the hospital length of stay, which was an average of 8.9 days ( $<<0.0001)$ in those who were on IMV. This is similar to another study of heroin overdose patients in the ICU with a mean hospital length of stay reported as eight days [18].

Limitations identified include the means of data collection of these patients, which was through the hospital billing system ICD-9 CM. This method is prone to missing some admissions for opioid-related complications. Also, being administrative data, this creates the opportunity to miss out on some clinical details that might be useful when analyzing what forms of intervention can be proffered. Such clinical details would be things like how many times was the patient on IMV in the same admission. This might give us more information about how the patient was managed and what complications they experienced during hospitalization. However, one of the strengths of our study is the availability of both clinical and demographic data across the United States and the fact that it is a large database. This large database increases the power of the study and the generalizability of our research findings. This study answers some of the questions asked in previous studies about predictors of hospitalizations in opioid overdose patients, which will guide policy and interventions that will limit hospital admissions and avoid a prolonged length of stay in the health care facility [3].

\section{Conclusions}

The prevalence of opioid overdose and the need for IMV increased over the five-year study period reflecting an increase in the relatively high in-hospital mortality of opioid overdose patients on IMV. These findings emphasize the need for a better understanding of the predictors of IMV use in hospitalized opioid patients to create a more strategic approach for their hospital care. There is a need to provide interventions that support more critical care resources and the expansion of primary prevention measures.

\section{Additional Information \\ Disclosures}

Human subjects: Consent was obtained by all participants in this study. Animal subjects: All authors have confirmed that this study did not involve animal subjects or tissue. Conflicts of interest: In compliance with the ICMJE uniform disclosure form, all authors declare the following: Payment/services info: All authors have declared that no financial support was received from any organization for the submitted work. Financial relationships: All authors have declared that they have no financial relationships at present or within the previous three years with any organizations that might have an interest in the submitted work. Other relationships: All authors have declared that there are no other relationships or activities that could appear to have influenced the submitted work.

\section{References}

1. Hua A, Haight S, Hoffman RS, Manini AF: Endotracheal intubation after acute drug overdoses: incidence, complications, and risk factors. J Emerg Med. 2017, 52:59-65. 10.1016/j.jemermed.2016.07.114

2. Wilson N, Kariisa M, Seth P, Smith H, Davis NL: Drug and opioid-involved overdose deaths-United States, 2017-2018. MMWR Morb Mortal Wkly Rep. 2020, 69:290-297.

3. Pfister GJ, Burkes RM, Guinn B, et al.: Opioid overdose leading to intensive care unit admission: epidemiology and outcomes. J Crit Care. 2016, 35:29-32. 10.1016/j.jcrc.2016.04.022

4. Rudd RA, Paulozzi LJ, Bauer MJ, et al.: Increases in heroin overdose deaths-28 states, 2010 to 2012 . MMWR Morb Mortal Wkly Rep. 2014, 63:849-854.

5. CDC. Drug-poisoning deaths involving heroin. United States, 2000-2013 . (2015). Accessed: July 01, 2020: https://www.cdc.gov/nchs/products/databriefs/db190.htm. 
6. CDC. Overdose opioid. Understanding the epidemic. (2018). Accessed: July 01, 2020: https://www.cdc.gov/drugoverdose/epidemic/index.html.

7. Stevens JP, Wall MJ, Novack L, Marshall J, Hsu DJ, Howell MD: The critical care crisis of opioid overdoses in the United States. Ann Am Thorac Soc. 2017, 14:1803-1809. 10.1513/AnnalsATS.201701-022OC

8. Unick GJ, Rosenblum D, Mars S, Ciccarone D: Intertwined epidemics: national demographic trends in hospitalizations for heroin-and opioid-related overdoses, 1993-2009. PloS One. 2013, 8:54496. 10.1371/journal.pone.0054496

9. Surveillance Research Program. Joinpoint trend analysis software. (2019). Accessed: June 01, 2020: https://surveillance.cancer.gov/joinpoint/.

10. Prevention: opioid data analysis and resources . (2018). Accessed: July 01, 2020: https://www.cdc.gov/drugoverdose/data/analysis.html.

11. Hasegawa K, Brown DF, Tsugawa Y, Camargo Jr CA: Epidemiology of emergency department visits for opioid overdose: a population-based study. Mayo Clin Proc. 2014, 89:462-471. 10.1016/j.mayocp.2013.12.008

12. Hasegawa K, Espinola JA, Brown DF, Camargo CA: Trends in US emergency department visits for opioid overdose, 1993-2010. Pain Med. 2014, 15:1765-1770. 10.1111/pme.12461

13. CDC. Drug-poisoning deaths involving opioid analgesics: United States, 1999-2011 . (2014). Accessed: July 01, 2020: https://www.cdc.gov/nchs/products/databriefs/db166.htm.

14. Siegler A, Tuazon E, Bradley O'Brien D, Paone D: Unintentional opioid overdose deaths in New York City, 2005-2010: a place-based approach to reduce risk. Int J Drug Policy. 2014, 25:569-574. 10.1016/j.drugpo.2013.10.015

15. Walley AY, Xuan Z, Hackman HH, et al.: Opioid overdose rates and implementation of overdose education and nasal naloxone distribution in Massachusetts: interrupted time series analysis. BMJ. 2013, 346:f174. 10.1136/bmj.f174

16. Kim D, Irwin KS, Khoshnood K: Expanded access to naloxone: options for critical response to the epidemic of opioid overdose mortality. Am J Public Health. 2009, 99:402-407. 10.2105/AJPH.2008.136937

17. Orsini J, Din N, Elahi E, Gomez A, Rajayer S, Malik R, Jean E: Clinical and epidemiological characteristics of patients with acute drug intoxication admitted to ICU. J Community Hosp Intern Med Perspect. 2017, 7:202207. 10.1080/20009666.2017.1356189

18. Grigorakos L, Sakagianni K, Tsigou E, Apostolakos G, Nikolopoulos G, Veldekis D: Outcome of acute heroin overdose requiring intensive care unit admission. J Opioid Manag. 2010, 6:227-231. 